\title{
Aprender a ser - a importância dos métodos pedagógicos
}

\section{Learnign to be - the importance of pedagogical methodos}

\author{
Catarina Moreira, Clara Oliveira \\ Instituto de Educação, Universidade do Minho, Portugal
}

\begin{abstract}
Resumen
Nesta reflexão oferece-se um destaque à importância dos métodos pedagógicos, tendo em consideração as definições de “educação ao longo da vida” e de “aprendizagem ao longo da vida” apresentadas respetivamente pela UNESCO e pela Comissão Europeia; temos em consideração outros tópicos, bem como a abordagem de definições relevantes, como "aprender a aprender”, “aprender a desaprender” e abordagem humanística. da educação Nos focamos nos métodos círculos de estudo e grupos de encontro, tendo como autor de referência preferencial, Carl Rogers, para além de outros autores relevantes para a justificação das definições/ conceitos.
\end{abstract}

Palabras clave: métodos pedagógicos, educação ao longo da vida, aprender a aprender.

Esta reflexão centra-se na importância dos métodos pedagógicos, tendo em consideração, por um lado, a definição segundo a UNESCO, de "educação ao longo da vida”, que se caracteriza por desenvolver todo o potencial educacional, ou seja, não são limitados a um período de presença exclusiva na escola, sendo os indivíduos os agentes da sua própria educação, o que permite uma interação contínua entre pensamentos ações e ensino - aprendizagem. Esta interação é que gera um tipo de educação capaz de possibilitar competências em diversos ramos do conhecimento e de utilizar todos os meios necessários para as alcançar, podendo assim desenvolver em pleno a personalidade de cada adulto.

Por outro lado, a aprendizagem ao longo da vida segundo a Comissão das Comunidades Europeias, surge como a aprendizagem na vida adulta para a estratégia desta mesma, pois existe uma aquisição de conhecimento contínuo ininterrupto, sugerido no Memorando (2000) “do berço à sepultura” ou como sugere Silvestre (2011) “aprender até morrer”.

Dado a continuidade da importância da aprendizagem ao longo da vida, alguns conceitos relevantes a abordar são, segundo Silvestre (2011) “aprender a aprender”, que "advém de toda a aprendizagem feita nos diferentes contextos, tempos e domínios”, e "neste mundo em galopante transformação” torna-se importante um novo conceito, “aprender a desaprender”, isto é, "a pessoa tem de ser humilde, inteligente e capaz de muita plasticidade mental”, para escolher de forma mais eficaz quais os conhecimentos a preservar e quais a desconsiderar.

Nesta abordagem de aprendizagem ao longo da vida é relevante ter em consideração o pensamento de Paulo
Freire (1975) de uma educação problematizadora, cujos autores são simultaneamente educadores e educandos, orientando-se no sentido da humanização e do pensar autêntico. Seguindo esta reflexão, será relevante mencionar a abordagem humanística, que enfatiza a experiência, a liberdade e a responsabilidade no desenvolvimento pessoal de adultos. "A aprendizagem surge como um processo através do qual os adultos concretizam o seu potencial individual; ao mesmo tempo, a aprendizagem consiste num processo de auto-atualização" (Bélanger, 2011: 35-39; Finger \& Asún, 2003: 61-70).

Para além da aprendizagem ser considerada como um processo individual, facilitando a aprendizagem com princípios pedagógicos não-diretivos, que consistem na aprendizagem autónoma com colaboração de um facilitador, que interfere o menos possível, "a educação é vista como um processo permanente e realizado ao longo da vida, pelo qual se criam condições para que todos (sem exceção) cresçam e se desenvolvam em todos os seus estádios e capacidades de uma forma global e harmoniosa e equilibrada até à plena realização pessoal e comunitária” Ribeiro Dias citado por Silvestre (2011).

A relevância destes conceitos (educação ao longo da vida" e "aprendizagem ao longo da vida”) podem-se verificar numa decisão da Europa, que no decorrer do ano 1996, deu asas à iniciativa do Ano Europeu da Educação e Formação ao Longo da Vida, tendo como ideia principal a criação de conjunturas que possibilitem a todos os cidadãos ter acesso ao conhecimento durante toda a vida, estando esta ideia manifesta na conceção democrática do funcionamento das nossas sociedades.

Apesar dos diversos métodos pedagógicos conhecidos serem importantes e de forte relevância para a educação e aprendizagem ao longo da vida, na nossa opinião os mais adequados são os métodos pedagógicos: Círculos de Estudo e Grupos de Encontro.

O primeiro é considerado como um método por excelência da educação de adultos, como já referimos anteriormente, na educação ao longo da vida. Este método é relevante, para os participantes dos círculos de estudo, porque lhes permite estudar para ficarem mais desenvolvidos, isto é, destina-se a adultos que se pretendam desenvolver, sendo que se deverá ter em consideração as suas experiências pessoais, familiares e profissionais.

No que diz respeito ao método pedagógico Grupos de Encontro, tem como objetivo principal, segundo Rogers (1980), acentuar o crescimento pessoal e o desenvolvimento e aperfeiçoamento da comunicação e relações interpessoais, através de um processo 
experiencial. Torna-se evidente que o método tem forte relevância e ligação com os conceitos de "educação ao longo da vida” e "aprendizagem ao longo da vida”, sendo um processo onde os indivíduos constroem em grupo a sua própria aprendizagem, nas mais diversas dimensões.

Foi implementada numa Universidade Sénior, uma atividade denominada por Baú de Ideias, que consiste na dinamização da sua biblioteca, que potencia na sua utilização, para além de fomentar a leitura, o pensamento crítico e a exposição de ideias entre o grupo de participantes. Neste Grupo de Encontro, as conclusões e interpretações de cada indivíduo não são ajuizadas como certas ou erradas, mas sim compreendidas e justificadas por diferentes meios, isto é, textos, poemas, fotografias, letras de música, entre outros. Com esta atividade conseguiu realizar-se uma fusão de ambos os métodos pedagógicos anteriormente explicados, o que possibilita que exista um debate onde se discutem diversos temas, tendo em consideração alguns pequenos textos, com por exemplo "Uma Carta para Garcia” de Elbert Hubbard e o “ Poema Ecológico” de Chefe Seattle, que permitem a discussão de diversos temas em cada um desses textos, por exemplo: política, economia, gestão de empresas, culturas, ambiente, família, valores, religião, entre muitos outros.

Após cada sessão concluímos que o debate era facilmente iniciado, pelo facto das perspetivas retiradas após a leitura dos pequenos textos serem tão distintas entre cada indivíduo. Por vezes, foi invocado o passado e as experiências (pessoais, familiares e profissionais) que, na maior parte dos casos, estão guardadas no "fundo do baú", e que exemplificam as ideias retiradas dos textos. Com isto, faz-se, assim, a auto-atualização, desenvolvendo-se cada uma das pessoas em todas as suas dimensões, emergindo inclusive um crescimento cognitivo e intelectual. Exemplificando, através da sessão onde foi explorado o "Poema Ecológico", foram desencadeadas diversas opiniões e recordações, tais como- a infância (brincadeiras e livros apelativos aos índios), o cuidado a ter com a natureza, a preocupação com o estado atual do meio ambiente, os interesses económicos e alterações de políticas (pagamento pelos sacos plásticos), consciência da problemática ambiental (o que leva a alterações do quotidiano).
Para concluir, estes métodos suportam as finalidades dos conceitos acima referidos, porque os objetivos de ambos baseiam-se no desenvolvimento holístico e sustentam-se na aprendizagem que adquire significado para a nossa profissão, para a nossa casa, para os nossos tempos livres e para a nossa atividade pública. A seleção destes métodos como os mais indicados para responder às finalidades dos conceitos apresentados não foi simples, uma vez que muitos oferecem uma forte relevância, direta ou indireta, para a "educação ao longo da vida" e da "aprendizagem ao longo da vida" Interessante será referir que a educação e aprendizagem ao longo da vida começam a obter uma dimensão importante, para além da referida pela UNESCO e pela Comissão Europeia, pois atualmente a ênfase oferecida a este âmbito é constante em todas as políticas, instituições/associações e indivíduos.

\section{Referencias}

Comissão das Comunidades Europeias (2000). Memorando sobre Aprendizagem ao Longo da Vida. Bruxelas: Memorando sobre Aprendizagem ao Longo da Vida.

Freire, P. (1975). Pedagogia do Oprimido. Afrontamento: Porto.

Silvestre, C. A. (2011). Educação e Formação de Adultos e Idosos - Uma nova oportunidade. Instituto Piaget: Lisboa.

UNESCO (2009). Recomendação sobre o Desenvolvimento da Educação de Adultos, UNESCO Relatório Global sobre Aprendizagem e Educação de Adultos. UNESCO: Nova Iorque.

Rogers, C. (1970). Grupos de encontro. Lisboa: Moraes Editores.

Vallgarda H. \& Norbeck J. (1986). Para uma Pedagogia Participativa - O círculo de estudo e o guia de estudo. Gráfica Cruz: Braga. 